\title{
INFORMATION TECHNOLOGIES, READING, AND THE FUTURE OF HIGHER EDUCATION ${ }^{1}$
}

\begin{abstract}
The article addresses the challenge for universities and colleges to prepare students for the world they inhabit through relevant course offerings and new approaches to teaching. Unfortunately, these structures of higher education still resemble chapels, where the professor is 'priest,' and with a pedagogy that is informed by monologue, methodological nationalism, and a general lack of awareness of the rapidly changing social and physical world around us. Starting with the Gutenberg revolution, and following the ideas of Marshall McLuhan, Sven Birkerts and Joseph Brodsky, the article approaches the consequences of the new information technologies that are profoundly rewiring our minds and replacing our ability to think critically. The author asks: what might education look like today? How might we challenge young people to learn how to think? The first task appears to critique and transform the political architecture of classrooms and the teacher centeredness of pedagogical activity, replacing monologue with dialogue. Students need to be shown how to critically distance themselves from the seductions of information technologies, and educational institutions should return to requiring deep reading and discussion of extended narratives.
\end{abstract}

KEYWORDS: higher education, information technologies, critical thinking

\section{INTRODUCTION}

Recent discussions among students, professors, and administrators regarding the current status of the social sciences, liberal arts, and the humanities has motivated me to offer some reflections, not least because I think the discussions often assume a context that has largely disappeared. To begin however, let me make clear a foundational assumption that will inform my remarks and that I will elaborate upon as I proceed: that is, that the fundamental challenge for

\footnotetext{
1 This paper originated as a presentation made to the IAU College Board of Trustees in Washington, D.C., on 19 February 2015. It was modestly revised in May 2021. It is not for publication or copy without the express permission of the author. (C) James M. Skelly, 2021.
} 
universities and colleges rests with the academic and intellectual vitality of its course offerings. Concern with recruitment, finances, and the quality and character of student learning outcomes, will all increasingly depend upon whether or not we are clearly preparing students for the world that they will inhabit during the remaining years of this century. I dare to say that many of the institutions, and the faculty upon which they depend, that I am familiar with in the United States and in Europe, are not doing that. Instead, they seem to be preparing students for an idealized version of education from the last half of the $20^{\text {th }}$ century, with classrooms that still resemble chapels, where the professor is 'priest,' and with a pedagogy that is informed by monologue, methodological nationalism, and a general lack of awareness of the rapidly changing social and physical worlds that we humans inhabit.

Zygmunt Bauman [2001:128] has captured the broader crisis of educational institutions in the context of contemporary post-modern circumstances:

"The present educational crisis is first and foremost a crisis of inherited institutions and inherited philosophies. Meant for a different kind of reality, they find it increasingly difficult to absorb, accommodate and hold the changes without a thorough revision of the conceptual frames they deploy, and such a revision, as we know from Thomas Kuhn, is the most overpowering and deadly of all the challenges thought may encounter."

\section{THE GUTENBERG REVOLUTION}

Bauman's notion that the educational crisis is "a crisis of inherited institutions and inherited philosophies," can be given historical context if one recognizes that most of the professors, their academic disciplines, and the institutions that they inhabit are the progeny of the revolution engendered by Johannes Gutenberg and the literacy that came with the reading of books. Febvre and Martin in their work on the broad impact of printing emphasize the revolutionary character of the printed book by noting that it "created new habits of thought not only within the small circle of the learned, but far beyond, in the intellectual life of all who used their minds" [1990:10-11]. Most notable in this regard were the new habits of thought that Martin Luther engendered and which were made widely available because of the printing press. Elizabeth Eisenstein observed that "the advent of printing was an important precondition for the Protestant Reformation taken as a whole; for without it one could not implement 'a priesthood of all believers'" [2012:171].

The necessary precondition to create the new priesthoods, both religious and secular, was that print culture unlike scribal culture had made texts stable, 
because, as James Gleick [2012:400] noted: "Before print, scripture was not truly fixed," but print in contrast "was trustworthy, reliable and permanent." Furthermore, "All forms of knowledge achieved stability and permanence.....simply because there were many copies." The stability and permanence of the forms of knowledge that print engendered, and Luther's emphasis on individual conscience with regard to scripture, "prepared the way," as Erik Erikson has observed, "for the series of concepts of equality, representation, and self-determination which became in successive secular revolutions and wars the foundations not of the dignity of some, but of the liberty of all" [1993:231]. Thus, Marshall McLuhan could assert that, "Western man knows that his values and modalities are the product of literacy" [19G7:2G9].

McLuhan however also worried that it was "necessary to understand the power and thrust of technologies to isolate the senses and thus to hypnotize society," because the "somnambulist conforming of beholder to the new form of structure renders those most deeply immersed in a revolution the least aware of its dynamic," and "it is felt, at those times, that the future will be a larger or greatly improved version of the immediate past" [Ibid: 272 - emphasis in original]. The revolution fostered by information technologies in the past two plus decades has not only hypnotized our societies, but most significantly, the hypnosis is central to the current crisis of our educational institutions. As Sven Birkerts noted just over 25 years ago in his work on the fate of reading in the electronic age, "we are in the midst of an epoch making transition," and "that the societal shift from printbased to electronic communications is as consequential for culture as was the shift instigated by Gutenberg's invention of moveable type" [1994:192].

Birkerts was particularly concerned "that while circuit and screen are ideal conduits for certain kinds of data....they are antithetical to inwardness" because "circuit driven communications are predicated upon instantaneousness." In contrast, "To the degree that we immerse ourselves in a book......we relinquish the governing construct of the now, exchanging it for content, feeling, and absorption" [Ibid: 193]. Birkerts went on to claim "that the wager is intuitively clear: we gain access and efficiency at the expense of subjective self-awareness." [Ibid: 220]. Joseph Brodsky captured the deeper political and psychological problem in his 1987 Nobel lecture when he argued that, "though we can condemn the material suppression of literature - the persecution of writers, acts of censorship, the burning of books - we are powerless when it comes to its worst violation: that of not reading the books." "For that crime," he said, "a person pays with his whole life; if the offender is a nation, it pays with its history" [Brodsky, 1987]. 


\section{THE INFORMATION TSUNAMI}

The scale of the knowledge problem engendered by the information tsunami is captured in a study conducted a few years back at the University of Southern California which indicated that using digital and analog devices we were then able to store 295 exabytes (put 20 zeros after the 295) of information which is 315 times the number of grains of sand in the world. Even ten years ago, according to Science Daily (2011), humans were successfully sending 1.9 zettabytes of information through broadcast technology such as televisions and GPS units. That's equivalent to every person in the world reading 174 newspapers every day. And, Thomas Barnett, the Director of Thought Leadership for Cisco Systems Worldwide Service Provider Marketing Group claims [2011] we are now in what is being characterized as the "Zettabyte Era." To visualize a zettabyte, one can think of 3G million years of HD video, or the volume of the Great Wall of China if you allow an 11oz cup of coffee to represent a gigabyte of data.

The deeper social-psychological problem embedded in this tsunami of information that we in educational and other institutions face, is that information has become increasingly independent of meaning. In Freeman Dyson's commentary in a New York Review of Books essay ten years ago on James Gleick's book, The Information: A History, a Theory, a Flood, Dyson cited the work of the so-called "father" of information theory, Claude Shannon. Shannon had controversially noted, as Dyson pointed out, that "information could be handled with greater freedom if it was treated as a mathematical abstraction independent of meaning." Dyson further suggested that the resulting "immense size of modern databases....gives us a feeling of meaninglessness," but that it is "our task as humans to bring meaning back into this wasteland" [2011].

\section{CONSEQUENCES}

One consequence of the information tsunami at an individual level is that because of the neuro-plasticity of the human brain, our minds are being rewired in accord with the new information technologies in a manner that is much more profound than the major re-wiring that occurred as the result of the Gutenberg revolution. As the researcher Jane Healy pointed out thirty years ago, there was increasing evidence to indicate that television was actually bringing about a restructuring of the human brain, as widespread reading undoubtedly began to do five hundred years ago. Healy argued that "the ability to read, and the related ability to write, are not hard-wired into the human brain." Children must learn to make meaning out of printed texts, and the work of such learning is substantially more difficult than the work of watching television. Among the negative effects of television watching on children according to Healy, was the inability "to sustain 
attention independently, stick to problems actively, listen intelligently, read with understanding, and use language effectively." Healy suggested therefore that it was no wonder that a University of Michigan study showed that when asked whether they would choose their fathers or television, if forced to make the choice, over $30 \%$ of four and five year olds chose television [Skelly, 1995].

The re-wiring that began manifesting with television has of course been heightened by the new information technologies associated with the internet that now increasingly permeate everyday life throughout the world, as Nicholas Carr has so convincingly argued in his book The Shallows [2010], which elaborated on his rather well-known article, "Is Google Making Us Stupid?" [2008]. Drawing on the work of neuroscientists and brain researchers, Carr argued "that long-term memory is actually the seat of understanding" because it stores not just facts but complex concepts, or 'schemas'." Since "the depth of our intelligence hinges on our ability to transfer information from working memory to long-term memory and weave it into conceptual schemas," the problem that develops when the cognitive load of our working memory exceeds the "mind's ability to store and process the information" is that "we can't translate the new information into schemas" and "it becomes harder to distinguish relevant information from irrelevant information, signal from noise" [2010:124-125]. As Sven Birkerts also noted [1994:18], one consequence is that "the world we have known, the world of our myths and references and shared assumptions is being changed by a powerful, if often intangible, set of forces."

However, it isn't simply being changed by powerful forces, it is replacing the ability to think critically. Over a decade ago, a close friend of mine, Bud Mehan, who is a well-known educationalist, and senior faculty member at UC San Diego, provided me with an interesting anecdote regarding the capacity of students to think critically that I have mused upon ever since. He said that he had been the "tag-along spouse" at an international education conference with his wife at which he had met many young people who had in his words, "excellent values." "But," he said, "they had no capacity for critical analysis!" In my reflections upon this insight, it seemed clear that the source of this distortion was that the total information environment had become the total educational environment, or what Raymond Williams [19G7:15] intuitively foresaw over 50 years ago as the "permanent education."

Thus, one of the initial tasks is to understand the character of that permanent education today, and the difficulty that students face in sorting the meaningful from the meaningless. Given the overwhelming amount of information in disconnected bits that students are swimming in, it has become increasingly difficult for them to develop a coherent sense of what is happening in the actual world rather than in the limited virtual worlds they increasingly seem to inhabit. I sincerely wonder, given the tsunami of information that we have been subjected 
to in the last three decades, if we are not seeing the development of a kind of cyber peasantry in which the mind has a mass of bits of information strewn incoherently about in a manner that mimics the images of the devastation that followed the horrific tsunami in Japan some years ago.

Let me provide some examples of how I think the problem manifests concretely in students. The British lecturer Mark Fisher characterizes his students as suffering from "hedonic lassitude," such that when students are asked "to read for more than a couple of sentences....many will protest that they can't do it" because "it's boring." And, it's not the content of the reading that students complain about Fisher says, "it is the act of reading itself that is deemed to be 'boring'." Fisher suggests that a fundamental mismatch has developed between the increasing numbers of post-literate students who are "'too wired to concentrate,' and the confining concentrational logics of decaying disciplinary systems" - in other words, the disciplines that inform our teaching! Thus, rather than being dyslexic, Fisher argues that increasing numbers of students are actually "post-lexic" because they can process the "image-dense data very effectively without any need to read."

Birkerts also speaks of the students he had in a class on "The American Short Story" in a similar manner. He queried them on their responses to Henry James's "Brooksmith," and there was a general complaint summed up by one student who said, "I dunno, the whole thing just bugged me - I couldn't get into it." In further discussions with the students about their responses, Birkerts learned "that they were not, with a few exceptions, readers-never had been; that they had always occupied themselves with music, TV, and videos;" and "that they had difficulty slowing down enough to concentrate on prose of any density" [1994:17-19].

In my own experience, twelve years ago while I was Visiting Professor of Peace Studies in Derry at the Magee campus of the University of Ulster, I told two of the seemingly intelligent students from the American Middle West who were studying there the legendary story of Nobel Peace Laureate John Hume, who, standing on the bridge separating Strasbourg and France from Germany, had said that if the French and Germans could create an enduring peace, so too could the Irish and British. John Hume was then not only the most famous resident of Derry, but also a Professor on the Magee campus - one bumped into him regularly - and the two students had been on the campus and living in Derry at this point for three months, but mentally they were still in Indiana and Kansas. They had no idea who John Hume was, let alone how he was inspired to initiate the Peace Process in Northern Ireland. I told this story to a colleague in Strasbourg who had also been teaching American students, and he did me one better - he had given a talk to his students about the origins of French republicanism and mentioned the Enlightenment - yes, as you may have guessed, none of them had heard of, or knew 
anything about, the Enlightenment. My suspicion was that they might have guessed that "The Enlightenment" was a film starring Matt Damon!

Of course, their education was not enhanced by the fact that between 2008 and 2011 the University of Ulster had gradually decided to eliminate courses in Philosophy, History, and Politics from the curriculum at the Magee campus of the university in Derry, nor when the Vice-Chancellor told a meeting of faculty and staff in December of 2011 that, "I don't think anyone comes to Magee to explore the meaning of life." Instead, he said, the university curriculum must be focused on "skills" and "employability." This is a general tendency in educational institutions today, and therefore public discourse has become increasingly debased and ignorance becomes increasingly acceptable.

And when I took up the position of Interim Director of the Baker Institute at Juniata College in 2012 after living in Europe for most of the previous 20 years, I was astounded to see how pervasive this kind of ignorance was, and how easily the new information technologies colluded functionally in this phenomenon. One concrete consequence of this was how readily students copied or unthinkingly used the work of others and presented it as their own. One might call this "plagiarism," but in some cases, believe it or not, I became convinced that students didn't actually realize that they were plagiarizing!

In a noteworthy instance, students in an introductory class in Peace and Conflict Studies were meant to explore the process of institutionalizing peace - in Northern Ireland, for example, in the final course essay. One student submitted a paper that was superficially what we might call "pretty" - it had a fair number of quotes from well-known people about peace spread throughout the paper, rather as though the student had sketched flowery images around the margins of the essay, or was advertising a product called "Peace." She ended the essay with a quote from Eleanor Roosevelt. When I subsequently asked her who Eleanor Roosevelt was, a pained look spread across her face, and after some delay she quietly uttered that she didn't know, but then a tiny light bulb seemed to go on, and she said, "Teddy Roosevelt's wife??"

I then asked her where she had gotten this and the other quotations enthusiastically, she said, "brainyquotes.com!" I suppose this is the website for people with insufficient grey matter of their own!

There was an interesting sequel to this story however, which I think captures the even deeper problem.

About ten days after I had the conversation with the student, I was sitting next to a faculty member from the College of Information Sciences and Technology at Penn State University on a flight out of Dulles airport, and I told her the story of the brainy quotes student. When I finished my tale of woe, she looked at me and said, "Well, I use brainy quotes! But I always look up who the person is." 
The student, and undoubtedly the professor as well, had understood a key element of what passes for "knowledge" today. Not only was critical thinking about an issue unnecessary, but presentation was more important than substance. It was another manifestation of the dominance of the culture of advertising whereby the seductive quality of the object, in this case a term paper, as well as the student herself, became more important than the quality of the analysis informing how peace could be institutionalized. Although I doubt that she had read Be Your Own Spin Doctor [Richards: 1998 - emphasis in original], the ethos that "you can spin doctor YOURSELF into greater prominence and enhance your reputation with colleagues, friends, neighbours and opinion-formers," is one that she had undoubtedly internalized.

\subsection{Colonization of attention}

Unfortunately, I don't think the students are atypical of those who reside in academic institutions. Instead, like increasing numbers of those who ostensibly come to learn, many faculty members also have difficulty developing a coherent sense of what is happening in the actual world, as well, because of the knowledge problem created by the flood of information. A faculty member at a liberal arts college on the East Coast of the United States told me the story that in the fall of 2013, at the height of the Snowden' revelations when Daniel Ellsberg was regularly to be seen and heard on every form of major media, he was invited to give a major public lecture on surveillance and secrecy at the college. When Ellsberg's visit was mentioned on separate occasions to two senior members of the faculty, one of whom was the Chair of the college's Communication Department, they each said exactly the same thing: "Who's that?" The "system," if you will, does not want a broadly educated citizenry, and therefore mirrors Orwell's insight in 1984 where Winston reads the initial chapter, "Ignorance Is Strength," of Emmanuel Goldstein's, "Theory of Oligarchical Collectivism." In that chapter, Goldstein/Orwell makes clear that there is no problem with the proletariat having intellectual freedom because "they have no intellect." That's where we're headed, I fear.

Sven Birkerts pointed to the root of our difficulties in a 2010 essay on "Reading in a Digital Age." It wasn't just the information glut that was the source of our problems, but the character of the information technologies as well, and the manner in which they contribute to the fragmentation of attention:

"When there is too much information, we graze it lightly, applying focus only where it is most needed. We stare at a computer screen with its layered windows and orient ourselves with a necessarily fractured attention. It is not at all surprising that when we step away 
and try to apply ourselves to the unfragmented text of a book we have trouble. It is not so easy to suspend the adaptation."

In a Commencement address at Juniata College in Pennsylvania early in the past decade, Maryanne Wolf, the director of the Tufts University's Center on Reading and Language Research, who wrote Proust and the Squid: The Story and Science of the Reading Brain, claimed that we "need to transmit a mode of learning that is not content with the ever more immediate, ever more passive reception of information," and that we must "never let the distinctions among information, knowledge, and wisdom be lost to the next generations."

Wolf however, has found that she too has developed problems with sustained reading. As Michael Rosenwald wrote in the Washington Post a year ago, Wolf "sat down one evening to read Hermann Hesse's The Glass Bead Game" following a day in which she had scrolled through the internet and a multitude of emails. Her response - "I'm not kidding: I couldn't do it. It was torture getting through the first page. I couldn't force myself to slow down so that I wasn't skimming, picking out key words, organizing my eye movements to generate the most information at the highest speed. I was so disgusted with myself."

Instead of struggling, Wolf might have been encouraged to try the then new app called "Spritz" that speeds up your reading "without having to move your eyes." According to its developers, Spritz speeds up your reading because, "Removing eye movement associated with traditional reading methods not only reduces the number of times your eyes move, but also decreases the number of times your eyes pass over words for your brain to understand them." So much for sustained reflection then!

Our students who suffer what Maryanne Wolf struggled with are among the multitude that Richard Arum and Josipa Roksa have characterized as "academically adrift" in their book on "limited learning on college campuses." Arum and Roksa found that a significant percentage of students - nearly 50\% showed "no statistically significant gains in critical thinking, complex reasoning, and writing skills," and spend their college years doing as little as possible to attain a certificate that attests to their having successfully completed the requirements to receive an undergraduate degree (2011:3G). That this has profound implications for the social, political, and economic institutions that depend on the insights of those who can think critically, should be obvious. Birkerts again notes the problematic consequences when he argues that "our entire collective subjective history- the soul of our social body-is encoded in print" and that these are "in effect, the cumulative speculations of the species." Ultimately, he says, "Our historically sudden transition into an electronic culture has thrust us into a place of unknowing" [1994:20-21]. 
This "place of unknowing," and the failure to think critically, is my ultimate nightmare. It is a nightmare that is fundamentally informed by Hannah Arendt's reflections on Adolph Eichmann. In a lecture and subsequent essay [1971:417] published after the publication of Eichmann in Jerusalem, Arendt noted that however monstrous Eichmann's deeds were "the only specific characteristic one could detect in his past as well as in his behavior during the trial and the preceding police examination was something entirely negative: it was not stupidity but a curious, quite authentic inability to think." And therefore, as Birkerts laments, "Looking at our society, we see no real leaders, no larger figures of wisdom. Not a brave new world at all, but a fearful one" [1994:20].

Thus one aspect of the challenges that higher education institutions have to face is, I think, how to structure its educational offerings so that they overcome the increase in institutionalized ignorance, and instead grounds students in the world of concrete events rather than in the simulacra of the virtual world. These pedagogical initiatives should require deep reading and the development of some significant psychological distance from the seductions of information technologies, including those that allow students to stay in Kansas while they are actually in Strasbourg or Derry.

\section{CRITICAL THINKING SEMINARS}

In order to challenge the information overload, the colonization of attention, the lack of deep reading, and the failure to think critically, along with colleagues from institutions in Europe and the United States, we have offered twelve primarily three-week seminars in the summers and late spring between 2012 and 2017 related to "critical thinking in the information age." These seminars have to date included: The Political Economy of Information Technologies; History and Social Change; Self and Identity; The Question of Method; and, The Political Economy of Love. In 201G we also held a one-week seminar that included participants from the leadership of AEGEE - The European Students' Forum on Education, Information Technologies, and New Subjectivities.

Nearly 50 students and faculty participants participated in the 12 seminars that the Centre on Critical Thinking organized between 2012 and 17, many in several seminars. The participants had been resident in 22 countries including Austria, Brazil, Croatia, France, Georgia, Germany, Hungary, Ireland, Israel, Italy, Lithuania, Macedonia, Netherlands, Palestine, Poland, Portugal, Rumania, Slovakia, Spain, Sweden, United Kingdom, and the United States. From the beginning in 2012 we attempted to create a "social world" - Una Comunidad de Pensamiento - for students and faculty to assist both in developing a critical analytical narrative that will help them to make sense of our world during the 
three weeks of each seminar and beyond. Seminar sessions were structured to last 3 hours each morning from Monday through Friday, and they were followed by a communal lunch, and later in the day by dinner together. Generally, students were meant to read two or three books per week, and approximately 100 pages per day, and therefore leaving no time for excursions or other contemporary entertainments during the three weeks of the seminar.

Most importantly, seminar participants were asked to restrict their use of information technologies other than books. For pedagogical reasons, including what Carr and others suggested was the increase in attention deficit disorders engendered by internet usage, we asked participants to completely disconnect from the internet except to respond to emails during a two-hour period on Saturday afternoons. Therefore, participants were asked not to bring mobile phones, computers, tablets, or so-called smart phones to any seminar sessions and to disconnect them while they are in residence except for the two hour period on Saturday afternoons for responses to email only. Surfing the internet, following hyperlinks, etc., were all strongly discouraged in order to keep a participants' focus on seminar content. Prospective students who are addicted to Facebook and other social networking sites, were discouraged from applying, and it was gently suggested that they instead read The Winter of Our Disconnect by Susan Maushart [2010].

\section{G. ANALYSIS OF THE SEMINARS}

In the summer of 2015 Dr. Gyöngyi Fabian, a lecturer at Pannon University in Hungary, who had been engaged in exploring the social aspects of learning and teaching, joined the seminar on Self \& Identity at the Institute for Social \& European Studies in Koszeg, as a participant observer since she had a strong interest in critical thinking. She indicated that although "critical thinking is mainly discussed as an individual endeavor in current literature," what she observed in the seminar we were holding was "that developing critical thinkers can successfully be achieved through developing a learning community." She further noted that:

"The participants of the seminar have demonstrated a number of the dispositions which I understand are vital for critical thinking. They are courageous in revealing their positions, trustworthy, sensitive to different opinions, and first of all, open to interact with others without violating their personal domains. What is more, as skillful thinkers they are able to engage in discussions using the appropriate functional language of agreement, disagreement, making a point, etc. in a sophisticated manner." 
In Fabian's assessment, this behavior was "supported by the materials read" which "triggered serious and valuable ideas over a variety of topics of high concern, like social constructs, identity, power, language, gender issues, love and a lot more." The method of teaching that Fabian observed is not unlike what Zygmunt Bauman [2001:12G] argues for where "it is far from clear who acts as the teacher and who acts as the pupil, who owns the knowledge to be transmitted and who is placed at the receiving end of the transmission, and who decides which knowledge needs to be passed over and is worth appropriating."

Fabian further argues that she had "witnessed a way of teaching which is difficult to find in classrooms of post socialist cultures," and I would add, throughout the world. She suggested that, "The vibrant discussions, the deep sincerity and the critical attitude" she observed, "clearly stimulates learning efficiently." However, she concluded, the dominant "methods of frontal teaching, the common ways of transmission of knowledge, and teacher directed classroom management all featured by a high level of teacher centeredness," do not stimulate the efficient learning she observed in the seminars which provided "a successful model for approaching critical thinking in adult education."

\section{STUDENT CRITIQUES}

In addition to Fabian's observations, we also undertook an assessment of the experience of ten student participants in the seminars during the summer of 2014 through in-depth interviews in several areas including: an evaluation of the experience of disconnecting from information technologies: whether or not their capacity for deep reading increased; and how the seminars compared to other educational experiences the participants had previously participated in.

Somewhat to our surprise, though not wholly, students were very positive about disconnecting from information technologies. A student from Spain indicated that it made him reflect on how much he needed the internet and that he had realized "it's not as important" as he had previously thought, and that it's very good "for focusing more on what we were reading," as well as on "personal relations, and when you talk to people you're talking to people, you're not thinking other things or taking a look to the telephone." Similarly, a student from the United Kingdom said, "It really opens up space for reflection, and that she felt "like it's an utter relief," because she previously thought she associated "my emails and all the things that I regularly do on the internet with some pressure, psychological pressure, just because I need to respond, and expectations of being, in contact all the time... So yeah, I find it, just, liberating, quite a relief, relaxing." And a Croatian student exclaimed that disconnecting "was really powerful" in making her realize how much she "was relying on technological stuff in everyday life," but also how 
much she "was deeply embraced by all this technopoly." The most expressive response came from a Lithuanian student who said that all he could think about was "the "privilege" of disconnecting." He contrasted this with the "pressure to be part of it all, be informed, networked and stuff" and that by being "in an environment where there is no pressure like that," he was able to "see that a different way of living and thinking is possible."

We were obviously less surprised that with such positive responses to disconnecting from information technologies, students were able to engage, and enthuse, about deep and sustained reading. The U.S. students however, would appear to have had greater difficulty with attention to reading prior to the seminars, perhaps because of greater addiction to information technologies. One student from the United States for example, answered in the affirmative that he had indeed been able to engage in deep reading, and then he suggested why this was so. He indicated that, "While I don't usually have problems focusing while I'm reading, I don't really get the sense of being immersed in books anymore, especially when I'm in school or surrounded by technology." Another student suggested that he didn't "read a lot in general, and then coming here I read more than I ever have in that short of a period of time," because "there's so much more time than when you're at home," and "there are so many more things that I'm constantly worrying about, than when I'm here." Another U.S. student said something similar: "Well, the length of my attention span for reading has heightened, and also I'm interested in reading deeper, or more than just glancing through an article. I was skimming things. My attention span was gone." A fourth U.S. student said, "I found myself able to read for the first time in years, because I didn't really feel any compulsion to check up on things, I didn't really have distractions around. If I was just sitting somewhere quiet with a book I could really focus all of my attention solely on the book."

The European students didn't seem to have been as overwhelmed as the Americans by reading prior to the seminars, but nonetheless, one could still see the general trend. The student from Croatia exclaimed, "Oh yes. Like never before. Because you're not distracted so you're able to follow your own thoughts more deeply, and being reflective in ways that you can't do when you're connected constantly." The Romanian student similarly said, "Yes, of course. It really had...... therapeutic effect" since "it really allows you to be there (well, here!) and only focus on what you're reading." She also noted that it gave her back sovereignty over the knowledge she was acquiring - "what's great about it is that it gives you back control over how you digest information, and what you're reading." Perhaps most profound were the comments of a Lithuanian students, who said that for him, "the seminar changed how I read books" because he was "a lot more capable of trying to get at the whole idea of the book, even if I did not like parts of it." 
In the final query in our study with the student participants, we asked them to compare their experience in the seminars with other educational experiences and how this affected their perspectives on education and pedagogy. In this instance, the students were overwhelmingly critical of the pedagogical approach in traditional educational institutions, and there was a strong consensus on this point from both the U.S. and the European students. Many of the students were critical of the 'teacher centeredness' of traditional educational experiences. One U.S. student, for example, said that:

"it's definitely unlike any traditional academic classes. And it's just a very different feeling than if you feel like you're learning in a factory, or getting a factory education, a one-size fits all, rather than really engaging in a critical thinking mindset. It reaffirmed the belief that I've had for a while that the student is certainly not...below a teacher," as "a teacher has a role to play in the classroom that is a little bit different from the student, but the two are not mutually exclusive and there definitely needs to be less of a, "I tell you what's going on," and more of a "let's explore this together..."

Another student from the U.S. indicated:

"I liked that it was a community, and that we were all discussing these ideas. I liked that I was focusing on one subject or topic at a time, and that was an astounding difference and made it all better. I wish I could do this for all of my education. It makes me wonder why education...... is so focused on discreet bits of knowledge that you can use to get a job, as opposed to wondering why we're here or wondering about the deeper structure of society."

The student from Romania said something similar. She indicated that at her university, "there was no exchange of information," but that information "was just being fed" and her professors were "very much pleased, that the 'audience' is able to reproduce the information and that's where it stops." The seminars, in contrast, she said, confirmed "the way it should be - what can be called 'education'." A Spanish student added further confirmation of this critique. He claimed that, "This kind of education was encouraging you to have deeper thinking about the meaning of what you're studying, and not just staying on the surface of things. I think that education should be more like this, that it's preparing people not only for performing a role or just finding a position, but for having deeper thinking about what you're going to do with your life and with your learning, and also your career."

The students from Croatia and Lithuania made further complementary statements. The Croatian student said that "there is a huge amount of freedom, 
intellectual freedom, in these seminars, which you can't have and you're not allowed to have during any other educational system or experiences. I always thought that the educational system is just deeply wrong, and should be changed, and this experience just made me more aware of that." The Lithuanian student indicated that the seminars had been "so much more superior to" his other educational experiences and was "what education basically should be. It's not putting information into people and trying to give them a certain set of very superficial skills or capacities, to meet very superficial requirements, but it is really giving people the capacity to think." One consequence for him was that "it makes it much more difficult to go back to any traditional forms of education because they seem absolutely superficial and that they don't facilitate any real understanding."

The penultimate critique of the dominant educational models came from a British student who said the following:

"With my undergraduate university experience, the paradigm was about passing exams so I was just playing the game really and just doing what I needed to do to pass and I wasn't engaging much more than superficially with the content. In terms of the education model all I can say is that it felt like a completely standardized form of education, where it was really just a means to an end and didn't at all challenge me to really learn how to think at all. I don't think I learned how to think. I just learned a bunch of knowledge, and I learned how to use criteria in order to be able to write a convincing essay, play the game, and pass. Which I did successfully, but it definitely wasn't education!"

\section{CONCLUDING REFLECTIONS}

"But it definitely wasn't education!" So, what might education look like today? How might we challenge young people "to really learn how to think"?? Quite obviously there are initiatives that should be taken at the primary and secondary levels, as well as in the home. But since my experience, and consequent analysis is focused on third-level education in universities and colleges, let me suggestion that overall, especially with the larger institutions, the habitualization that Bauman critiques, as well as the vested interests of various institutional actors, will make the task nearly impossible, at least until the crisis becomes much more problematic.

That said, it might be possible for smaller institutions - the independent liberal arts college in the United States, for example - to have sufficient innovative capacity to create a semester that performs the function of an "Intellectual Bootcamp." There are probably a small but significant number of students who 
long for a true in-depth education. As I have suggested in this article, the first task would be to critique and transform the political architecture of classrooms and the teacher centeredness of most pedagogical activity. Dialogue should surely replace monologues by the priest/professor. The twelve seminars we offered for five years might provide a model, but regardless of the structure, students should be taught how to distance themselves from the seductions of information technologies. In addition, educational institutions should not only stop touting "wired" learning, but return to a requirement for deep reading and discussion of extended narratives - in other words, books!

\section{REFERENCES \& NOTES}

Arendt, H. (1971): “Thinking and Moral Considerations: A Lecture” Social Research, 38(3): 417-44G.

Arum, R. and Roksa, J. (2011): Academically Adrift: Limited Learning on College Campuses. University of Chicago Press, Chicago

Barnett, T. (2011): The Dawn of the Zettabyte Era. http://blogs.cisco.com/news/the-dawn-of-the-zettabyteera-infographic

Bauman, Z. (2001): The Individualized Society. Polity Press, Cambridge

Birkerts, S. (1994): The Gutenberg Elegies: The Fate of Reading in an Electronic Age. Faber and Faber, London

Birkerts, S. (2010): "Reading in a Digital Age" The American Scholar https://theamericanscholar.org/reading-in-a-digital-age/

Brodsky, J. (1987): Nobel Lecture.

https://www.nobelprize.org/prizes/literature/1987/brodsky/lecture/

Carr, N. (2008): "Is Google Making Us Stupid? What the Internet is doing to our brains"

The

Atlantic

http://www.theatlantic.com/magazine/archive/2008/07/is-google-making-usstupid/30G8G8/

Carr, N. (2010): The Shallows. W. W. Norton, New York

Freeman, D. (2011): "How We Know" The New York Review of Books https://www.nybooks.com/articles/2011/03/10/how-we-know/

Eisenstein, E. (2012): The Printing Revolution in Early Modern Europe, second edition. Cambridge University Press, Cambridge

Erikson, E. (1993): Young Man Luther: A Study in Psychoanalysis and History. W. W. Norton, New York

Fabian, Gyöngyi, personal communication, 19 August 2015.

Febvre, L. and Martin, H. (1990): The Coming of the Book: The Impact of Printing 1450-1800. Verso, London

Fisher, M. (2009): Capitalist Realism. Zero Books, Winchester, UK 
Gleick, J. (2012): The Information: A History, A Theory, A Flood. 4th Estate, London

Maushart, S. (2010): The Winter of Our Disconnect. Profile Books, London

McLuhan, M. (19G7): The Gutenberg Galaxy: The Making of Typographic Man. University of Toronto Press, Toronto

Richards, P. (1998): Be Your Own Spin Doctor: A Practical Guide to Using the Media. Take That, London

Rosenwald, M. (2014): “How The Internet Is Making It Harder To Read Books,” Washington Post

The Science, Spritz (2015)

https://web.archive.org/web/20150913052G21/http://www.spritzinc.com the-science/

Skelly, J. (1995): "Pau, Cultura i Communicacio," in: Martinez Guzman, V. (ed): Teoria de la Paz. Nau Libres, Valencia, Spain

University of Southern California. (2011, February 11). How much information is there in the world?. ScienceDaily.

http://www.sciencedaily.com/releases/2011/02/110210141219.htm

Williams, R. (19G7): Communications. Barnes and Noble, New York

Wolf, M. (2008): Proust and the Squid: The Story and Science of the Reading Brain. Harper, New York 